\title{
Cell count and lymphocyte immunophenotyping of bronchoalveolar lavage fluid in healthy Brazilian children
}

\section{To the Editors:}

Bronchoalveolar lavage (BAL) is an invaluable tool in the diagnosis and follow-up of childhood lung diseases and is considered to be a safe procedure with low complication rates [1]. The information gathered through the interpretation of the BAL cellular profile, clinical findings and thorax imaging provide a clinical decision without the need for more invasive methods, such as an open-lung or transbronchial biopsy [2, 3]. Furthermore, T-lymphocyte flow cytometry immunophenotyping has also proved to be another diagnostic tool for lung diseases in paediatric patients [4].

The interpretation of BAL cellular profiles in children with lung diseases is performed via a comparison with reference values produced by studies conducted with healthy children [5]. Most of these studies were conducted in Europe in the mid-1990s, during laryngeal stridor management [2,6-8] or with children undergoing elective surgery under general anaesthesia for nonpulmonary illnesses [3,9]. However, to date, no similar study has been conducted in a low- or middle-income country.

This study was conducted to assess the total and differential BAL count, and to conduct lymphocyte subset analysis in Brazilian children from low-income families without lung diseases.

12 children from 1 to 8 yrs of age without lung diseases and who had undergone elective orthopaedic surgeries under general anaesthesia were studied. Inclusion criteria were: no history of lower respiratory tract symptoms; no upper respiratory tract infections in the previous 30 days; no systemic disorders; no atopy; and normal findings on physical examination and on bronchoscopy. We excluded children with positive BAL bacterial cultures and those exposed to tobacco smoke during pregnancy.

The research protocol was approved by the Ethics in Research Committee of the Universidade Federal de Minas Gerais (Belo Horizonte, Brazil). BAL was performed following the approval of the surgical and anaesthesia teams, and the informed written consent of parents.

BAL was performed via a paediatric flexible fibreoptic bronchoscope with a 3.5-mm outer diameter (Olympus BF3C40; Olympus, Hamburg, Germany), through the orotracheal tube, immediately after intubation. All children were given general anaesthesia with intravenous sevoflurane and propofol. The BAL procedure protocol followed the European Respiratory Society recommendations [5]. Only those cells with typical morphology were differentially counted.

Table 1 shows the cell count results. A very small percentage $(<1 \%)$ of cells were epithelial, but were not included in the differential cell count, as was the case with red blood cells. A small percentage of basophils and monocytes was also observed $(<0.5 \%)$.

CD4+ and CD8+ T-lymphocyte immunophenotyping was performed in 10 out of 12 patients. The results of this are shown in table 2.

There is only one published study on BAL fluid reference values that recruited $>40$ individuals [3]. Probably due to ethical and operational constraints, the average population in other studies has been $\sim 13$ patients, which is similar to the number of children selected in the present study. This smaller sampling may be partially explained by the great operational difficulties involved in studying paediatric control subjects.

Regarding the total and differential cellular profile, it was observed in the present study that the values for the upper and lower limits presented were overlapping with those of almost every published study on this subject, while the number of cells per millilitre of BAL was slightly less than those of most other studies. However, it was similar to those found by RATJEN et al. [3], who also studied healthy children undergoing elective surgeries with no presence of atopic association.

The median neutrophil count was $<1.5 \%$, ensuring a lack of any inflammatory lung processes in the children studied. Some studies $[2,8,9]$ reported a higher median, which may be related to the selection criteria for patients. The lymphocyte count was slightly increased in the present study when compared with other studies and was also similar to those described by RATJEN et al. [3], who basically adopted similar inclusion criteria.

Eosinophils counts were slightly elevated in relation to the other studies, although an elevated value ( 3.6 cells per $\mathrm{mL}$ ) was also reported by RATJEN et al. [3]. A possible explanation for this finding can be related to the fact that the other studies were conducted in developed countries with lower rates of intestinal parasitosis. Even though that study did not specifically ask for family income, the authors were able to note during data collection whether subjects were from low-income

\begin{tabular}{|c|c|c|c|c|}
\hline \multirow[t]{2}{*}{ TABLE 1} & \multirow[b]{2}{*}{ Mean \pm SD } & \multirow[b]{2}{*}{ Median } & \multirow[b]{2}{*}{$\begin{array}{c}\text { Interquartile } \\
\text { range }\end{array}$} & \multirow[b]{2}{*}{ Range } \\
\hline & & & & \\
\hline Cells $\times 10^{4}$ per $\mathrm{mL}$ & $17.2 \pm 20.8$ & 8.3 & $5.4-20.9$ & $2.7-75.0$ \\
\hline Macrophages \% & $83.1 \pm 5.1$ & 84 & $78.9-87$ & 74-90 \\
\hline Neutrophils \% & $2.1 \pm 3.3$ & 1.2 & $0.3-2.3$ & $0-12$ \\
\hline Lymphocytes \% & $13.7 \pm 4.2$ & 13.5 & $11.1-16.6$ & $6-20.3$ \\
\hline Eosinophils \% & $1.1 \pm 1.0$ & 1 & $0.2-1.8$ & $0-3$ \\
\hline
\end{tabular}




\begin{tabular}{|c|c|c|c|c|}
\hline \multirow[t]{2}{*}{ TABLE 2} & \multicolumn{4}{|c|}{$\begin{array}{l}\text { CD4+ CD8+ T-lymphocyte percentage values } \\
\text { and the CD4+/CD8+ ratio in the study group }\end{array}$} \\
\hline & Mean $\pm S D$ & Median & $\begin{array}{l}\text { Interquartile } \\
\text { range }\end{array}$ & Range \\
\hline CD4+ \% & $30.9 \pm 10.5$ & 28.0 & $23.8-38.1$ & $19.9-54.6$ \\
\hline CD8+ \% & $42.6 \pm 8.9$ & 41.3 & $37.3-51.9$ & $27.7-56.7$ \\
\hline CD4+/CD8+ & $0.78 \pm 0.5$ & 0.65 & $0.5-0.88$ & $0.42-1.97$ \\
\hline
\end{tabular}

families. Therefore, the studied children may have come from communities with inadequate sanitation and living conditions.

Regarding macrophage counts, our results were similar to those found in other published studies. Also, CD4+/CD8+ ratio values found in this study were also similar to those described for healthy children [4, 8].

These peculiarities found in the BAL of healthy children should be considered when interpreting results from children with lung diseases. Thus, in our setting, the number of eosinophils and lymphocytes found in "normal" children's BAL seems to be slightly elevated in relation to the results of studies conducted in developed countries. Therefore, we could accept $\sim 2 \%$ eosinophils and $\sim 14 \%$ lymphocytes as BAL reference values for our setting.

In our view, advancements in understanding cellular and immunological processes in normal children will provide the basis for acquiring greater knowledge of infant and childhood lung diseases, and a better understanding of the way in which, in later phases of life, such respiratory diseases are manifested.

\section{I.F. de Mendonça Picinin*, P. Camargos*, R.F. Mascarenhas", S.M.E. Santos ${ }^{\top}$ and C. Marguet ${ }^{+}$ \\ *Pediatric Pulmonology Unit, "Clinical Pathology Division, University Hospital, "Dept of Propedeutics, School of Medi- cine, Federal University of Minas Gerais, Belo Horizonte, Universidade Federal de São João del Rei, São João del Rei, Brazil. 'Division of Paediatric Pulmonology, Allergy and Cystic Fibrosis, Charles Nicolle University Hospital, Rouen University, Rouen, France.}

Correspondence: P. Camargos, Federal University of Minas Gerais, Avenida Alfredo Balena, 190/Room 267, Minas Gerais,
Belo Horizonte, Brazil. E-mail: pcamargs@medicina.ufmg.br

Support Statement: P. Camargos is supported by the Brazilian research agencies Conselho Nacional de Desenvolvimento Científico e Tecnológico (CNPq) and Fundação de Amparo à Pesquisa do Estado de Minas Gerais (FAPEMIG). These research agencies had no influence on study design, collection, analysis or interpretation of data, writing of the report, or the decision to submit the paper for publication.

\section{Statement of Interest: None declared.}

Acknowledgements: The authors are indebted to R. Corrêa (Federal University of Minas Gerais, Belo Horizonte, Brazil) and P. Pitrez (Pontifical Catholic University of Rio Grande do Sul, Porto Alegre, Brazil) for reviewing the preliminary version of the manuscript.

\section{REFERENCES}

1 de Blic J, Marchac V, Scheinmann P. Complications of flexible bronchoscopy in children: prospective study of 1,328 procedures. Eur Respir J 2002; 20: 1271-1276.

2 Midulla F, Villani A, Merolla R, et al. Bronchoalveolar lavage studies in children without parenchymal lung disease: cellular constituents and protein levels. Pediatr Pulmonol 1995; 20: 112-118.

3 Ratjen F, Bredendiek M, Brendel M, et al. Differential cytology of bronchoalveolar lavage fluid in normal children. Eur Respir J 1994; 7: 1865-1870.

4 Ratjen F, Bredendiek M, Zheng L, et al. Lymphocyte subsets in bronchoalveolar lavage fluid of children without bronchopulmonary disease. Am J Respir Crit Care Med 1995; 152: 174-178.

5 de Blic J, Midulla F, Barbato A, et al. Bronchoalveolar lavage in children. ERS Task Force on bronchoalveolar lavage in children. Eur Respir J 2000; 15: 217-231.

6 Tessier V, Chadelat K, Baculard A, et al. A controlled study of differential cytology and cytokine expression profiles by alveolar cells in pediatric sarcoidosis. Chest 1996; 109: 1430-1438.

7 Clement A, Chadelat K, Masliah J, et al. A controlled study of oxygen metabolite release by alveolar macrophages from children with interstitial lung disease. Am Rev Respir Dis 1987; 136: 14241428.

8 Riedler J, Grigg J, Stone C, et al. Bronchoalveolar lavage cellularity in healthy children. Am J Respir Crit Care Med 1995; 152: 163-168.

9 Koh YY, Jung da E, Koh JY, et al. Bronchoalveolar cellularity and interleukin-8 levels in measles bronchiolitis obliterans. Chest 2007; 131: $1454-1460$.

\section{Clinical relevance of mixed respiratory viral infections in adults with influenza A H1N1}

To the Editors:

Throughout the pandemic circulation of the 2009 influenza A $\mathrm{H} 1 \mathrm{~N} 1$ virus (A/H1N1p), concomitant detection of other respiratory viruses in the same patient was reported [1, 2], but their clinical relevance remains unknown. Mixed respiratory viral infections in adults have scarcely been studied. The aim of this study was to assess both the incidence of multiple viral respiratory infections and their clinical significance in adult patients with confirmed A/H1N1p. 